\title{
Enfermedad de la orina con olor a jarabe de arce: revisión de tres casos clínicos.
}

Disease of maple syrup urine: review of three clinical cases.

Mayra Alejandra López Serrano. ${ }^{1} \&$ Carlos Fernando Vaca Pazmiño. ${ }^{2}$

Recibido: 08-03-2017 / Revisado: 08-05-2017 Aceptado: 13-06-2018/ Publicado: 01-07-2018

\begin{abstract}
.
DOI: https://doi.org/10.33262/cienciadigital.v2i3.154
\end{abstract}

The Maple Syrup Urine Disease is a metabolic pathology that encloses the inborn errors of metabolism. This is produced by an alteration in the metabolism of three of the essential branched chain amino acids that are: valine, leucine and isoleucine. The main effect of accumulated metabolites occurs in the brain, causing neurological problems such as those that occurred in the newborns of our study; that is why the importance of a correct and early diagnosis, to further reduce their mortality. Regarding treatment, it must be urgent since serious encephalopathy or death may occur; this is based on the reduction of the high concentrations of the aforementioned amino acids and adequate nutritional support. Three cases registered in the Neonatology Service of the Ambato General Teaching Hospital of the same city, Ecuador are presented below.

Keywords: Metabolic Disease, Amino Acids, Encephalopathy, Mortality.

\section{Resumen.}

La Enfermedad de la Orina con olor a Jarabe de Arce se trata de una patología metabólica que encierra a los errores innatos del metabolismo. Esta se produce por una alteración en el metabolismo de tres de los aminoácidos esenciales de cadena ramificada que son: valina, leucina e isoleucina. El efecto principal de los metabolitos acumulados se produce en el cerebro, ocasionando los problemas neurológicos como los que se manifestó en los recién nacidos de nuestro estudio; es por eso la importancia de un correcto y precoz diagnóstico, para además disminuir su mortalidad. Respecto al tratamiento este debe ser urgente puesto que puede

\footnotetext{
${ }^{1}$ Médico Residente de Neonatología, Hospital General Docente Ambato, Ecuador, serranoale_@hotmail.com

${ }^{2}$ Jefe de Servicio de Neonatología, Hospital General Docente Ambato, Ecuador, cfvaca_14@ hotmail.com
} 
producirse encefalopatía grave o muerte; este está basado en la reducción de las altas concentraciones de los aminoácidos antes mencionados y de un apoyo nutricional adecuado. Se presenta a continuación tres casos registrados en el Servicio de Neonatología del Hospital General Docente Ambato de la misma ciudad, Ecuador.

Palabras Claves: Patología Metabólica, Aminoácidos, Encefalopatía, Mortalidad

\section{Introducción.}

La enfermedad de la orina con olor a jarabe de arce (MSUD) por sus siglas en ingles Maple Syrup Urine Disease es una enfermedad metabólica causada por una deficiencia en la actividad del complejo de la deshidrogenasa de los cetoácidos, acumulándose en la sangre aminoácidos: valina, isoleucina y leucina ${ }^{(1,2)}$ (Valladares, 2012) ("Enfermedad de la orina...", 2004), cuya acumulación produce una encefalopatía neonatal grave, que de no ser diagnosticada y tratada de forma precoz y oportuna, lleva posteriormente a una aparición de secuelas neurológicas permanentes. (3) ("Enfermedades relacionadas con...", 2014) Esta entidad tiene un manejo médico específico en fase aguda y un tratamiento a largo plazo para evitar secuelas y mortalidad, de ahí la importancia de tenerla en cuenta como diagnóstico diferencial (4) (Suarez,2015) En 1954, Menkes y colaboradores informaron sobre un nuevo síndrome en cuatro hermanos que presentaban un cuadro de disfunción cerebral progresiva con excreción por orina de una substancia no habitual con olor que recordaba al jarabe de arce, por lo cual denominaron a este síndrome con el nombre de enfermedad de la orina con olor a jarabe de Arce. ${ }^{(5)}$ (Busto, 2014) Esta es una enfermedad metabólica hereditaria extremadamente rara y se hereda con carácter autosómico recesivo, afecta por igual a ambos sexos. (4,6) (Suarez,2015) (“Transplante de hígado...”, 2016) Su incidencia es de 1/ 200.000 recién nacidos y 1:200 en comunidades menonitas estadounidenses y de Oriente Medio, por su alta consanguinidad en este grupo étnico. ${ }^{(1)}$ (Valladares, 2012) Esta patología es un desorden producto de la mutación del complejo Deshidrogenasa de Cetoácidos de Cadena Ramificada (BCKDH por sus siglas en inglés de Branched-chain alpha-keto acid dehydrogenase), encargado del segundo paso catabólico en la degradación de los aminoácidos ramificados: leucina, isoleucina y valina; la acumulación de estos produce una encefalopatía neonatal grave con alto riesgo de secuelas neurológicas permanentes y de muerte sin tratamiento adecuado. ${ }^{(4)}$ (Suarez,2015) En su forma clásica afecta a los neonatos o lactantes en los primeros meses de vida con cuadros de acidosis y cetosis graves, de alta mortalidad y alto grado de secuelas neurológicas irreversibles. ${ }^{(7)}$ (Serra, 2017)

Es necesario diferenciar la fase en la que se encuentra el paciente (fase aguda o fase de mantenimiento). Los objetivos en la fase de descompensación metabólica aguda se basan en tres puntos: eliminar los metabolitos tóxicos, soporte nutricional y conseguir anabolismo. La utilización de fórmulas dietéticas modificadas artificialmente constituye uno de los pilares del tratamiento en estos pacientes. ${ }^{(1)}$ (Valladares, 2012) Estos casos 
descritos a continuación sirven de ilustración a los profesionales de la salud que enfrentan pacientes encefalopáticos en la Unidad de Recién Nacidos (URN,) para que tengan en cuenta el diagnóstico de Enfermedad de Orina en Jarabe de Arce (EOJA).

\section{Presentación de casos clinicos.}

1.- El primer caso clínico se trata de una $\mathrm{RN}$ (recién nacido) a término femenina nacida de una madre de 17 años sin antecedente patológicos de importancia por parto distócico en nuestra Unidad de Salud, con un peso de $2630 \mathrm{~g}$, talla $47 \mathrm{~cm}$, PC $33 \mathrm{~cm}$ y un APGAR 8-9, permanece en alojamiento conjunto y a las 48 horas de vida es dado de alta. Posteriormente a los 6 días de vida es traído a emergencia por padres, los cuales refieren que RN no se alimenta adecuadamente desde hace 24 horas previas a su ingreso, además presenta hipoactividad y deposiciones verdosas por 8 ocasiones. Se le valora y al examen físico se presenta hipoactivo pero reactivo al manejo, ictérico zona II de Kramer, fontanela anterior normotensa, regular reflejo de succión, extremidades tono y movilidad disminuidas. La paciente es ingresada al servicio de Neonatología para observación y realización de exámenes respectivos, se realiza exámenes de laboratorio incluyendo para infección, los cuales reportan un PCR de $10.6 \mathrm{mg}$, un hemocultivo con crecimiento de cocos Gram positivos (S. epidermidis), niveles de Ac. Láctico de $4.69 \mathrm{mmol} / \mathrm{L}$; respecto a exámenes de neuroimagen se le realiza un Eco transfontanelar el cual nos reporta una mala diferenciación entre la sustancia gris y blanca y con flujos normales. A los tres días de hospitalización se percibe un olor característico en la orina del RN, por lo que se sospecha de un trastorno innato del metabolismo y se realiza los exámenes correspondientes para su diagnóstico, ya pensando en un resultado positivo se prescribe alimentación diluida (50\% leche y $50 \%$ aguda) al fin de disminuir la ingesta de aminoácidos. Recién nacido durante su hospitalización sigue permaneciendo hipoactivo, irritable al manejo, con regular reflejo de succión, reflejo plantar y palmar débil y con abolición de otros reflejos: Búsqueda, Galant y Glabelar Se recibe resultados de Cromatografía de aminoácidos en plasma: Leucina ++, Isoleucina ++ , Valina ++ , además screening metabólico con un reporte de Leucina de $5.9 \mathrm{mg}$ dando positivo para Enfermedad en Jarabe de Arce.

Imagen N.1: Recién nacida a los 4 días de hospitalización

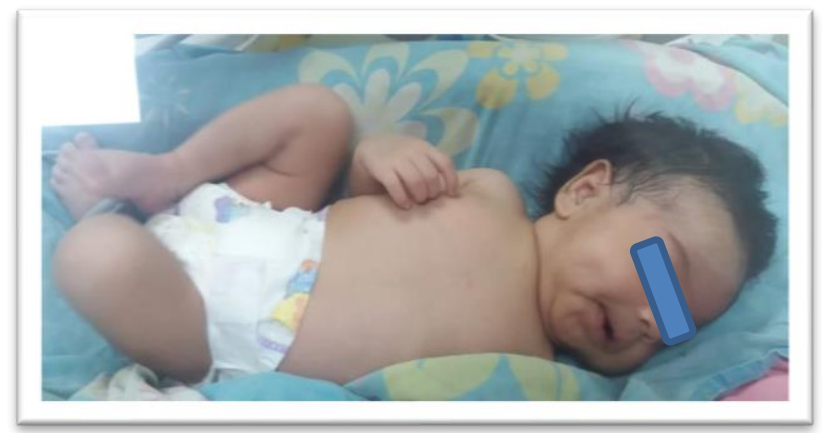

Elaborado por: Grupo de Investigación 
Recién nacida es dado de alta en buenas condiciones, con prescripción de leche especial el mismo que se enseña por parte de enfermería el modo de preparación. Posterior a su permanencia domiciliaria fallece.

2.- El segundo caso habla sobre un RN con madre de 24 años de edad sin antecedentes patológicos de importancia, que no se realiza controles prenatales ni ecos, pero si consumo de hierro y ácido fólico, embarazo sin complicaciones, el parto fue a término, eutócico en hospital, con una antropometría al nacimiento de $3140 \mathrm{~g}$ de peso, $46 \mathrm{~cm}$ de talla y $35 \mathrm{~cm}$ de perímetro cefálico y APGAR 8-9. Madre acude a emergencias de nuestra casa de salud con RN masculino de 7 días de vida, refiriendo que hijo hace 3 días previos presenta succión irregular, llanto fuerte con dificultad para descansar; 24 horas antes presenta mala succión y dificultad para deglutir, además vómitos por varias ocasiones. Se decide su ingreso y al examen físico se presenta hipoactivo pero reactivo al manejo, palidez generalizada, abdomen distendido y con ruidos hidroaéreos aumentados, extremidades hipertónicas (espásticas, semirrígidas) además ingresa con un peso de $2686 \mathrm{~g}$.

Imagen N.2: Recién nacido al momento del ingreso al servicio.

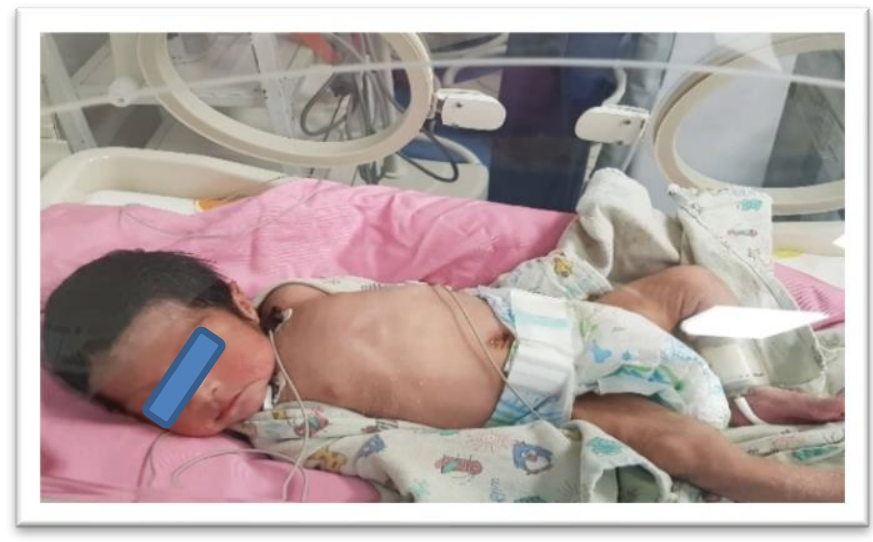

Elaborado por: Grupo de Investigación

Una vez en el servicio RN presenta buena succión y tolerancia oral, pero con una fontanela anterior abombada e hipertonía generalizada con tendencia al opistótonos; se realiza exámenes de laboratorio incluyendo para infección los cuales son negativos, incluyendo un eco transfontanelar con un reporte normal.

Dos días posteriores al ingreso presenta un olor característico en orina, como a madera, además de una crisis convulsiva de 45 segundos de duración tipo tónica acompañado de desaturación de hasta el 60\%, respiración entrecortada, bradipnea, bradicardia, por lo que se 
realiza nuevos exámenes de laboratorio, incluyendo además otro eco transfontanelar y un screening metabólico. RN con aumento de dificultad respiratoria por lo que se le pasa a DUOPAP nasal, se recibe reporte de eco el cual menciona Hemorragia de la Matriz germinal derecha e izquierda Grado I. Recién Nacido con persistencia de deterioro neurológico, por lo que se empieza a tratar como un Error innato del metabolismo, se deja en NPO por la mala tolerancia oral y déficit neurológico caracterizado por apertura ocular no espontanea, pupilas isocóricas hiporreactivas a la luz, no dirige mirada al estímulo auditivos, sostén cefálico débil e hipotonía muscular; recién nacido que por deterioro clínico que incluye además una neumonía recibe antibióticos y pasa a ventilación mecánica y a los 29 días de vida fallece.

Imagen N.3: Recién nacido a los 25 días de vida, se encuentra en ventilación mecánica.

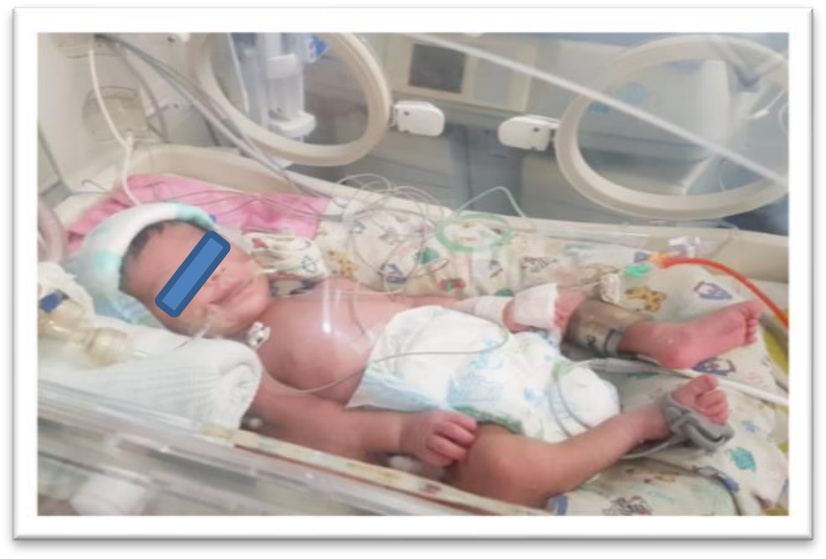

Elaborado por: Grupo de Investigación

A los 8 días de su fallecimiento se recibe resultados de screening metabólico, confirmado la sospecha de un error innato del metabolismo: Enfermedad de Orina con Olor a Jarabe de Arce.

3.- El tercer y último caso trata de un RN masculino a término hijo de una madre de 21 años de edad sin antecedentes, nacido con un Peso de $2880 \mathrm{~g}$, Talla $49 \mathrm{~cm}$ y PC de $34 \mathrm{~cm}$ y APGAR 9-10. Recién nacido es traído a nuestra Unidad de Salud a los 5 días de vida por referir somnolencia de 12 horas de evolución previo al ingreso y sin causa aparente, además madre refiere que hijo presenta vómitos por 2 ocasiones en poca cantidad y de contenido alimentario que no se acompaña de deposiciones diarreicas, alza térmica ni sintomatología respiratoria. 
En emergencia valoran a RN con palidez generalizada, hipoactividad, mala succión, hipertonía global, llenado capilar de 3 segundos y con una glucosa de $232 \mathrm{mg}$, por lo descrito anteriormente es ingresado al Servicio.

Al ingreso RN con olor de orina característico, por lo que se sospecha de una alteración del metabolismo de los aminoácidos por lo que se solicita un Screening metabólico ampliado y otros exámenes de laboratorio.

Es colocado en incubadora con apoyo de oxigeno por cánula nasal, pero a los 8 días de hospitalización RN con dificultad respiratoria por lo que es colocado en CPAP nasal y se mantiene con alimentación diluida (Leche de fórmula + agua destilada) para reducir aporte de aminoácidos.

Posteriormente paciente presenta descompensación clínica por lo que se le pasa a ventilación mecánica y se encuentra con tratamiento a base de antibióticos de primera línea, ya que no hay una buena respuesta se rota Antibióticos a base de Linezolid y Cefepime; además hemocultivo con crecimiento de S. Epidermidis.

Un mes posterior a su ingreso $\mathrm{RN}$ al momento hipoactivo, con nulo reflejo de succión, por lo que se alimenta mediante sonda orogástrica ya con Leche BCAD libre de aminoácidos Leucina, isoleucina y valina, además se recibe resultados de exámenes de screening metabólico dando un valor de Leucina de 3445 umol/L, Valina 867 umol/L, lo que confirma el diagnóstico de Enfermedad de orina con olor a jarabe de arce.

Imagen N.4: Recién nacido a los 28 días de vida.

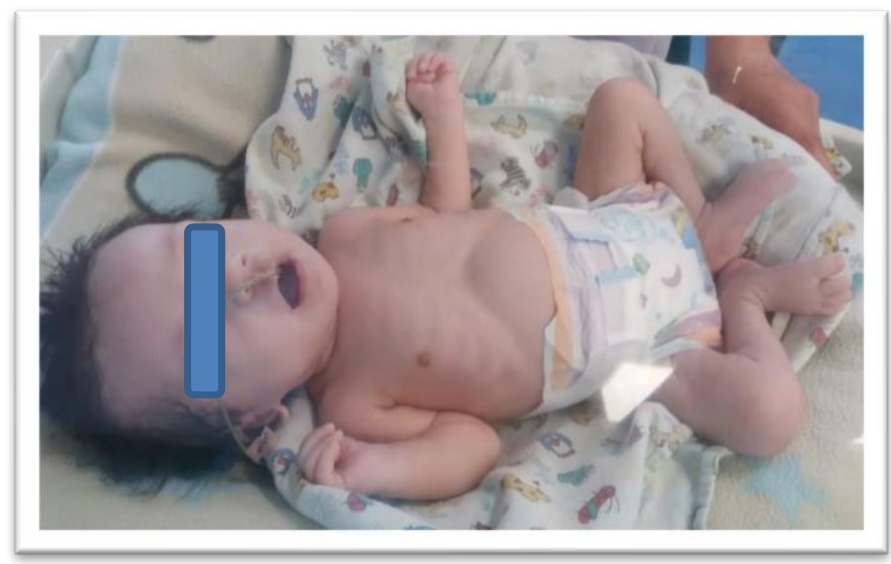

Elaborado por: Grupo de Investigación. 
Por limitaciones de recursos materiales en nuestro Hospital, el paciente fue transferido a una Unidad de Salud de tercer nivel en condiciones hemodinamicante estables.

Tabla N. I: Resumen de casos clínicos descritos

\begin{tabular}{|c|c|c|c|}
\hline & PRIMER CASO & SEGUNDO CASO & TERCER CASO \\
\hline EDAD MATERNA & 17 años & 24 años & 21 años \\
\hline $\begin{array}{c}\text { ANTECEDENTES } \\
\text { MATERNOS }\end{array}$ & Ninguno & Ninguno & Ninguno \\
\hline EDAD GESTACIONAL & A término $(41.3 \mathrm{~s})$ & A término (40s) & A término \\
\hline SEXO & Femenina & Masculino & Masculino \\
\hline APGAR & $8-9$ & $8-9$ & $9-10$ \\
\hline PESO NACIMIENTO & $2630 \mathrm{~g}$ & $3140 \mathrm{~g}$ & $2880 \mathrm{~g}$ \\
\hline $\begin{array}{l}\text { EDAD AL INICIO DE } \\
\text { LOS SINTOMAS } \\
\end{array}$ & 5 días & 4 días & 4 días \\
\hline $\begin{array}{c}\text { SIGNOS Y SINTOMAS } \\
\text { AL INGRESO } \\
\end{array}$ & $\begin{array}{c}\text { Hipoactivo, ictérico, tono y } \\
\text { movilidad disminuidas, regular } \\
\text { succión }\end{array}$ & $\begin{array}{c}\text { Succión mala y dificultad para } \\
\text { deglutir, irritable, vómitos, } \\
\text { pálido, hipoactivo, } \\
\text { extremidades hipertónicas }\end{array}$ & $\begin{array}{l}\text { Pálido, Somnolencia, } \\
\text { vómitos, mala succión, } \\
\text { hiperglicemia(232mg), } \\
\text { llenado capilar de } 3 \mathrm{seg} \text {. }\end{array}$ \\
\hline $\begin{array}{c}\text { SIGNOS Y SINTOMAS } \\
\text { DURANTE SU } \\
\text { EVOLUCIÓN } \\
\end{array}$ & $\begin{array}{c}\text { Olor característico en orina, } \\
\text { reflejos disminuidos y otros } \\
\text { abolidos }\end{array}$ & $\begin{array}{l}\text { Olor característico en orina, } \\
\text { Fontanela anterior abombada, } \\
\text { tendencia al opistótonos, crisis } \\
\text { convulsiva, deterioro } \\
\text { neurológico, mala tolerancia } \\
\text { oral }\end{array}$ & $\begin{array}{c}\text { Olor característico en } \\
\text { orina, hipoactividad, } \\
\text { nula succión }\end{array}$ \\
\hline $\begin{array}{l}\text { REQUIERE APOYO } \\
\text { DE OXÍGENO } \\
\end{array}$ & NO & $\begin{array}{c}\text { Oxigeno por cánula nasal, } \\
\text { posteriormente DUOPAP nasal } \\
\text { y finalmente ventilación } \\
\text { mecánica }\end{array}$ & $\begin{array}{c}\text { Oxigeno por cánula } \\
\text { nasal, posteriormente } \\
\text { CPAP nasal y después } \\
\text { ventilación mecánica } \\
\end{array}$ \\
\hline DIETA EMPIRICA & $\begin{array}{l}\text { SI, Leche de fórmula diluida con } \\
\text { agua destilada }\end{array}$ & $\begin{array}{l}\text { SI, Leche de fórmula diluida } \\
\text { con agua destilada }\end{array}$ & $\begin{array}{c}\text { SI, Leche de fórmula } \\
\text { diluida con agua } \\
\text { destilada }\end{array}$ \\
\hline DIETA ESPECÍFICA & NO & NO & $\begin{array}{l}\text { Leche BCAD libre de } \\
\text { aminoácidos Leucina, } \\
\text { isoleucina y valina }\end{array}$ \\
\hline
\end{tabular}


ISSN: 2602-8085

\begin{tabular}{|c|c|c|c|}
\hline $\begin{array}{l}\text { EXÁMENES DE } \\
\text { LABORATORIO }\end{array}$ & PCR: $10.6 \mathrm{mg}$ & $\begin{array}{c}\mathrm{Si} \text {, pero negativos al principio, } \\
\text { posteriormente positivos para } \\
\text { infección }\end{array}$ & $\begin{array}{l}\text { Hemocultivo con } \\
\text { crecimiento de } \mathrm{S} \text {. } \\
\text { Epidermidis }\end{array}$ \\
\hline $\begin{array}{c}\text { REQUIERE } \\
\text { ANTIBIÓTICOS }\end{array}$ & NO & SI & SI \\
\hline $\begin{array}{c}\text { EXÁMENES } \\
\text { ESPECIALES PARA } \\
\text { CONFIRMAR }\end{array}$ & $\begin{array}{l}\text { Cromatografía de aminoácidos en } \\
\text { plasma: Leucina }++ \text {, Isoleucina }++ \text {, } \\
\text { Valina }++ \text {, además screening } \\
\text { metabólico con un reporte de } \\
\text { Leucina de } 5.9 \mathrm{mg}\end{array}$ & $\begin{array}{c}\text { Screening metabólico confirma } \\
\text { Enfermedad de Orina con Olor } \\
\text { a Jarabe de Arce }\end{array}$ & $\begin{array}{l}\text { Screening metabólico } \\
\text { dando un valor de } \\
\text { Leucina de } 3445 \\
\text { umol/L, Valina } 867 \\
\text { umol/L }\end{array}$ \\
\hline $\begin{array}{l}\text { EXÁMENES DE } \\
\text { IMAGEN }\end{array}$ & $\begin{array}{c}\text { Eco Transfontanelar: mala } \\
\text { diferenciación entre la sustancia } \\
\text { gris y blanca y con flujos normales }\end{array}$ & $\begin{array}{c}\text { Eco Transfontanelar: } \\
\text { Hemorragia de la Matriz } \\
\text { germinal derecha e izquierda } \\
\text { Grado I }\end{array}$ & No se menciona \\
\hline FALLECE & Fallece posterior al alta & Fallece en el servicio & $\begin{array}{l}\text { Paciente transferido a } \\
\text { Hospital de III nivel } \\
\text { hemodinamicamente } \\
\text { estable }\end{array}$ \\
\hline
\end{tabular}

Elaborado por: Grupo de Investigación.

En la tabla descrita anteriormente podemos ver que los tres casos clínicos tienen mucha semejanza, comenzando por la ausencia de antecedentes de la madre y que todos los bebés nacieron a término, con un APGAR y peso adecuados. Respecto a la sintomatología en los tres casos el inicio de los síntomas se da aproximadamente a los 4 días de vida y con las mismas características neurológicas: hipoactividad y mala succión. La evolución clínica durante su estadía hospitalaria es desfavorable en todos los casos, además mencionando que solo en uno de ellos se pudo conseguir la leche especial para su tratamiento (BCAD libre de aminoácidos); en todos se confirmó la misma patología y lamentablemente fallecieron.

\section{Discusión.}

Las ventajas de un diagnóstico temprano de los trastornos innatos del metabolismo son obvias. Se ha determinado que cuando el tratamiento se inicia en las primeras 72 horas de vida, se reducen considerablemente la morbi-mortalidad, y los costos relacionados al cuidado de estos pacientes, lamentablemente este no es el caso de nuestros pacientes, cuyo diagnóstico se realizó pasado los 4 días de vida. ${ }^{(1)}$ (Valladares, 2012)

Los errores innatos del metabolismo son un grupo de desórdenes hereditarios producto de deficiencias enzimáticas que afectan diferentes vías metabólicas. La EOJA se trata de una 
patología autosómica recesiva, con una prevalencia estimada de 1/ 185.000 nacimientos. La MSUD ocurre en todos los grupos étnicos. Es más común en los menonitas en los Estados Unidos. Aproximadamente una de cada trescientos ochenta personas de origen menonita en los Estados Unidos tiene MSUD. También es más común en gente con ascendencia francocanadiense. ${ }^{(3,4)}$ (“Enfermedades relacionadas con...”, 2014) (Suarez,2015)

Esta se produce por una alteración en el metabolismo de tres de los aminoácidos esenciales, que se conocen como aminoácidos de cadena ramificada que son: valina, leucina e isoleucina y junto con el succinil CoA son los sustratos más importantes de la gluconeogénesis (formación de glucógeno a partir de ácidos grasos y proteínas en lugar de carbohidratos). ${ }^{(8)}$ (Leucinosis, 2015) El efecto principal de los metabolitos acumulados se produce en el cerebro, ocasionando en efecto tóxico directo que se traduce en disfunción y eventualmente muerte de las neuronas, ocasionando los problemas neurológicos como los que se manifestó en los recién nacidos de nuestro estudio. ${ }^{(1)}$ (Valladares, 2012)

Respecto a la fisiopatología se caracterizada por un marcado aumento de la concentración de leucina, isoleucina y valina (aminoácidos de cadena larga, BCAA), y al déficit de actividad del complejo multienzimático BCKD, por mutaciones en los genes que codifican sus componentes catalíticos, que son 3: E1 o descarboxilasa, E2 o dihidrolipoil transacilasa, este caso, y E3 o dihidrolipoil deshidrogenasa. Además, existe el caso de un RN de seis de vida el cual porta en homocigosis el cambio c.1128-1130 del CinsTT no descrito hasta el momento. ${ }^{(9)}$ (Carabaño, 2014)

Por otro lado, en la fisiopatología de la EOJA también incluyen cuatro factores primordiales: 1) Alteración de la osmolaridad: por acumulación de alfa cetoácidos y de Leucina. La consecuencia de esto será el edema cerebral, aspecto fundamental a tener en cuenta en el manejo médico agudo de estos pacientes.

2) Neurotoxicidad y Desbalance de neurotransmisores: a nivel de la barrera hematoencefálica (BHE) la Leucina compite con el trasportador de aminoácidos LAT1. Al saturarse este trasportador con la leucina se dejan de transportar a través de la BHE aminoácidos como triptófano, tirosina y metionina. Al ser estos precursores de neurotransmisores y donadores de S-adenosilmetionina, se genera un desbalance de neurotransmisores a nivel central, que explica muchos de los cambios neurológicos y psiquiátricos que se presentan a largo plazo en estos pacientes.

3) Stress oxidativo e inestabilidad genómica: Los hallazgos neuropatológicos en la EOJA incluyen desmielinización, incremento en la apoptosis y aumento del stress oxidativo.

4) Daño en otras vías metabólicas: El Alfa-ceto-isocaproato inhibe la Piruvato Deshidrogenasa, la Alfa cetoglutarato deshidrogenasa y otros componentes de la cadena de electrones mitocondrial. Esto explica, junto con lo mencionado en el punto tres, el déficit 
energético de estos pacientes y los niveles de ácido láctico incrementados. ${ }^{(4,10)}$ (Suarez,2015) (Céspedes, 2013)

Figura N.1: Vía metabólica de los aminoácidos ramificados: bloqueo por deficiencia del complejo multienzimático deshidrogenasa de los cetoácidos de cadena ramificada ${ }^{(5)}$.

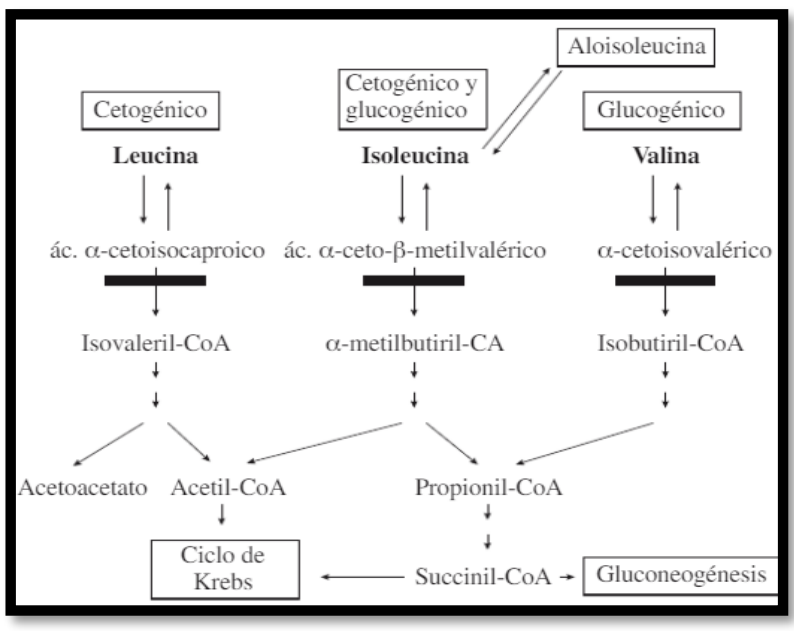

Elaborado por: Grupo de Investigación.

Existen 5 formas clínicas de presentación, que incluye la forma clásica, intermedia, intermitente, que muestran fluctuación del cuadro clínico y variabilidad de presentación en el tiempo; una sensible a tiamina que responde a dosis intermitentes de esta vitamina, y la forma atípica que cursa con acidosis láctica, pirúvica y elevación de alanina. (1) (Valladares, 2012)

\section{a.- Enfermedad de la orina del jarabe de arce clásica:}

Esta forma presenta las manifestaciones clínicas más graves y dentro de esta se encuentra nuestros casos clínicos. Los lactantes afectados, que son normales al nacer, presentan en la primera semana de vida una encefalopatía (término general para enfermedad del encéfalo) progresiva con vómitos y escasa tendencia a alimentarse; a los pocos días aparece letargia (carencia de energía) y coma. La exploración física revela la existencia de hipertonía (tono anormalmente elevado del músculo) y rigidez muscular, con intensos opistótonos (espasmo tetánico de los músculos de la nuca y el dorso, que arquea el cuerpo que se apoya sólo en la nuca y los talones).

Los períodos de hipertonía pueden alternar con fases de flacidez. Los signos neurológicos se confunden con frecuencia con los de una sepsis o una meningitis. La mayoría de los 
lactantes sufren convulsiones y habitualmente presentan. Sin embargo, a diferencia de la mayor parte de los cuadros hipoglucémicos, la situación clínica no mejora al corregir la concentración de glucosa en sangre.

El diagnóstico clínico de sospecha, se plantea ante el olor peculiar a jarabe de arce, similar al olor del azúcar quemado, de las secreciones corporales: orina sudor y el cerumen. ${ }^{(8,11)}$ (Leucinosis, 2015) (Lanza, 2017)

\section{b.- Enfermedad de la orina del jarabe de arce leve o intermedia:}

Suele presentarse a partir del periodo lactante y a lo largo de la infancia. Presentan anorexia persistente, vómitos crónicos, retraso mental y del crecimiento entre ligero y moderado; debido a la inespecificidad de estos síntomas los niños son diagnosticados entre los 5 meses y 7 años de edad. Pueden presentar el olor dulzón característico y son raros los casos que cursan con encefalopatía aguda. ${ }^{(8,12)}$ (Leucinosis, 2015) (Román, 2005)

\section{c.- Enfermedad de la orina del jarabe de arce intermitente:}

Aparece durante la edad preescolar o la adolescencia en pacientes previamente sanos. Cursa en forma de episodios recurrentes, que se desencadenan por infecciones, cirugía o tras una ingesta con sobrecarga de proteínas. Los síntomas más importantes son vómitos con el característico olor a jarabe de arce, letargia y deshidratación. En casos excepcionalmente más severos pueden presentar ataxia y coma. ${ }^{(8)}$ (Leucinosis, 2015)

\section{d.- Enfermedad de la orina del jarabe de arce con respuesta a la tiamina:}

La MSUD sensible a tiamina está poco caracterizada. Parece ser que por lo habitual se presenta después de la primera infancia con un fenotipo muy similar al observado para la MSUD intermedia. Entre las manifestaciones que se observan se incluyen problemas de rechazo alimentario, escaso crecimiento, olor a jarabe de arce en la orina y retraso en el desarrollo. Normalmente, los niños más mayores presentan problemas de aprendizaje. Al igual que sucede en la MSUD clásica, las situaciones de estrés fisiológico pueden desembocar en una descompensación aguda con anorexia, náuseas, vómitos (a todas las edades), ataxia (en lactantes y bebés más mayores), discapacidad cognitiva, trastornos del sueño, alucinaciones, hiperactividad, cambios de humor, distonía aguda/focal y coreoatetosis (en adultos), que puede progresar a estupor, coma y edema cerebral si no se trata al paciente. La tiamina (en dosis de 10 a $1.000 \mathrm{mg}$ al día) ha mejorado la tolerancia a la leucina en los pocos casos registrados de este subtipo de MSUD, pero sigue siendo necesaria cierta restricción de aminoácidos de cadena ramificada en la alimentación. ${ }^{(13,14)}$ (Wilcken, 2014) (“La extraña enfermeda que...”, 2015)

\section{e.- Deficiencia de la Subunidad E3:}


Es muy poco frecuente y el cuadro clínico es similar a la forma intermedia, con aumento de los aminoácidos VIL, ácido láctico, ácido pirúvico y $\alpha$-cetoglutárico. Entre los 2 y 6 meses se produce una importante acidosis láctica, con deterioro neurológico, hipotonía y movimientos anormales. ${ }^{(5)}$ (Busto, 2014)

Tabla N. II: Formas de presentación de la EOJA ${ }^{(7)}$

\begin{tabular}{|c|c|c|c|c|}
\hline \multirow[b]{2}{*}{ Fenotipo } & \multicolumn{2}{|r|}{ Clínica } & \multicolumn{2}{|c|}{ Bioquímica } \\
\hline & Inicio & Síntomas & BCAA, BCKA & Leucina $(\mu \mathrm{mol} / \mathrm{L})$ \\
\hline Clásica & $1^{a}-2^{a}$ semana de vida & $\begin{array}{l}\text { Rechazo alimentación } \\
\text { Letargia, hipotonia } \\
\text { Convulsiones } \\
\text { Cetoacidosis }\end{array}$ & $\begin{array}{c}\uparrow \uparrow \uparrow \uparrow \\
\text { aloisoleucina }\end{array}$ & $>>500$ \\
\hline Intermedia & 6 meses - 7 años & $\begin{array}{l}\text { Desmedro } \\
\text { Retraso psicomotor } \\
\text { Ataxia } \\
\text { Convulsiones }\end{array}$ & $\begin{array}{c}\uparrow \uparrow \\
\text { aloisoleucina }\end{array}$ & $400-2.000$ \\
\hline Intermitente & Lactante-adulto & $\begin{array}{l}\text { Crecimiento normal } \\
\text { Desarrollo psicomotor normal } \\
\text { Infección/estrés catabólico: ataxia, convulsiones, } \\
\text { cetoacidosis }\end{array}$ & Normal (fase asintomática) & $50-4.000$ \\
\hline Sensible a tiamina & Lactante & $\begin{array}{l}\text { Similar a forma "intermedia" } \\
\text { Desarrollo psicomotor normal }( \pm)\end{array}$ & $\downarrow \stackrel{\uparrow \uparrow}{\downarrow \text { con vitaminoterapia }}$ & $>50$ \\
\hline Deficiencia E3 & Lactante & $\begin{array}{l}\text { Inicio similar a forma "intermedia" } \\
\text { Progresivo y rápido deterioro neurológico } \\
\text { Acidosis láctica }\end{array}$ & $\uparrow \uparrow$ & $>400$ \\
\hline
\end{tabular}

Elaborado por: Grupo de Investigación

Respecto al diagnóstico es de vital importancia comprender que hasta que el paciente no manifieste signos de la EOJA va a ser imposible el diagnóstico. Se lo puede hacer mediante exámenes de laboratorio o de imagen.

\section{a.- Exámenes de laboratorio:}

Las concentraciones plasmáticas normales de los aminoácidos ramificados, 2-3 horas post ingesta, son: leucina 80-200 $\mu \mathrm{mol} / \mathrm{L}(1,0-2,6 \mu \mathrm{mg} / \mathrm{dl})$, valina 200-425 $\mu \mathrm{mol} / \mathrm{L}(2,3-5,0$ $\mathrm{mg} / \mathrm{dl})$ y isoleucina 40-90 $\mu \mathrm{mol} / \mathrm{L}(0,5-1,2 \mathrm{mg} / \mathrm{dl})$, recordando además que el análisis de aloisoleucina puede mejorar la sensibilidad, pero aun así algunos niños con variantes de MSUD pueden escapar a la detección. En la EOOJA estos BCAA, así como la aloisoleucina, se hallan elevados en todos los fluidos corporales (sangre, LCR, orina). La presencia de aloisoleucina es característica de la enfermedad. Los pacientes MSUD también excretan en orina, en concentraciones elevadas, los BCKA correspondientes a estos aminoácidos. La determinación de la concentración de los BCAA por cromatografía de intercambio iónico o electroforesis de alto voltaje, es clave para establecer el diagnóstico. $(5,15)$ Una vez obtenido el resultado anormal de la cromatografía de aminoácidos, se debe confirmar la enfermedad a través de cuantificación de aminoácidos por HPLC (cromatografía líquida de alta eficacia) la cual puede hacerse entre las 8 a 24 horas de vida. 
En este examen se evidencia la elevación de Leucina y Valina, disminución de Alanina y Glutamato y el aumento de aloisoleucina (aminoácido no proteico derivado de la leucina in vivo). ${ }^{(4)}$ (Suarez,2015)

Los estudios enzimáticos y moleculares confirman el diagnóstico. La demostración del defecto enzimático se lleva a cabo de forma indirecta midiendo la descarboxilación de [114C]- leucina en fibroblastos cultivados o en linfoblastos. El estudio molecular permite, además, la identificación de portadores en estas familias. ${ }^{(5)}$ (Busto, 2014)

\section{b.-Exámenes neuroradiológicos:}

Los recién nacidos y lactantes que presentan sintomatología neurológica tienen un edema cerebral generalizado. Este hallazgo se visualiza como áreas de hipoatenuación en los estudios de tomografía computarizada (TC) y de hipo/hiperintensidad en imágenes potenciadas en T1/T2. Estos hallazgos son más evidentes en la sustancia blanca profunda del cerebelo, vertiente dorsal del tronco del encéfalo, brazo posterior de ambas cápsulas internas, y más raramente en ganglios basales. Estas localizaciones suelen estar ya mielinizadas al nacimiento, por lo que estas imágenes radiológicas se describen como de desmielinización. Están en relación con las concentraciones plasmáticas de leucina, por lo que desaparecen al normalizar dichas concentraciones y pueden volver a presentarse si se abandona o relaja el tratamiento. La espectroscopia por resonancia magnética (RM) se ha mostrado útil para detectar descompensaciones metabólicas agudas al objetivar un pico invertido en el rango 0,9-1,0 pmm correspondiente a los aminoácidos leucina e isoleucina, que se pueden normalizar de manera concomitante con la mejoría clínica. ${ }^{(7)}$ (Serra, 2017)

En lo que tiene que ver al tratamiento es necesario diferenciar la fase en la que se encuentra el paciente (fase aguda o fase de mantenimiento). Los objetivos en la fase de descompensación metabólica aguda se basan en tres puntos: eliminar los metabolitos tóxicos, soporte nutricional y conseguir anabolismo. ${ }^{(1,16)}$ (Valladares, 2012) (Haldeman, 2011)

a.-Fase aguda: Es urgente el inicio del tratamiento puesto que puede producirse daño neurológico o muerte. Está basado en la reducción de las altas concentraciones de BCAA, disminución del catabolismo e incremento del anabolismo, junto a un apoyo nutricional adecuado. Los BCAA tienen un aclaramiento renal bajo, por lo que debe utilizarse técnicas extracorpóreas para su eliminación. Sigue siendo debatido cuál de ellas es la óptima. Se ha utilizado exanguinotransfusión, diálisis peritoneal, hemodiálisis y hemofiltración. (7,17) (Serra, 2017) (Aldimaz, 2008) La elección de una u otra técnica depende de las disponibilidades y experiencia de cada hospital. La segunda manera de eliminar el exceso de BCAA plasmáticos es incorporarlos a la síntesis proteica con medidas que induzcan al anabolismo, como es la nutrición parenteral y/o enteral con sonda nasogástrica continua. La nutrición parenteral debe hacerse con aportes de glucosa, lípidos y una mezcla de 
aminoácidos exenta de leucina, isoleucina y valina, la cual no siempre está disponible en los hospitales cuando es urgente su administración; por otra parte, aunque la administración de lípidos podría teóricamente comportar riesgos en pacientes comatosos por la hipotética neurotoxicidad de los ácidos. Si en 24 horas no hay mejoría clínica y analítica se debe valorar alguna de las técnicas extracorpóreas de eliminación de metabolitos tóxicos cuyas indicaciones se muestran en la Tabla II. ${ }^{(7)}$ (Serra, 2017)

Tabla

Indicaciones de extracorpóreas
1. Al diagnóstico:

- Leucina $>2.500 \mu \mathrm{mol} / \mathrm{L}(>33 \mathrm{mg} / \mathrm{dl})$

- Síntomas neurológicos graves

- Valoración individual en caso de:

- No tolerancia oral

- Cetoacidosis

- Más de 10-15 días de vida

2. Si tras 24 horas con dieta exenta de aminoácidos ramificados: - Leucina $>1.000 \mu \mathrm{mol} / \mathrm{L}(>13 \mathrm{mg} / \mathrm{dl})$

- Descenso de leucina $<500 \mu \mathrm{mol} / \mathrm{L}(6,5 \mathrm{mg} / \mathrm{dl})$ en 24 horas - No mejoría clínica
N.III: técnicas

(7)

Elaborado por: Grupo de Investigación

b.- Fase de mantenimiento: El objetivo de la fase de mantenimiento es conseguir un estado nutricional normal con la prevención de deficiencias de macro y micronutrientes, mantener un crecimiento adecuado, evitar las crisis de descompensación, y en su caso detectarlas precozmente.

Estos objetivos generales, iguales a los de otras aminoacidopatías, deben ser minuciosamente seguidas en la MSUD ya que por sus especiales características fisiopatológicas un mal control puede desencadenar crisis de descompensación con posibles graves consecuencias. Por ello se requiere fijar unos objetivos terapéuticos (Tabla IV) cuyo control es necesario para evitar las complicaciones citadas. Los controles se deben realizar midiendo semanalmente los aminoácidos de cadena ramificada durante la fase inicial, para luego hacerlos menos frecuentes. ${ }^{(1)}$ (Valladares, 2012) 
Tabla N.IV: Objetivos Terapéuticos ${ }^{(7) .}$

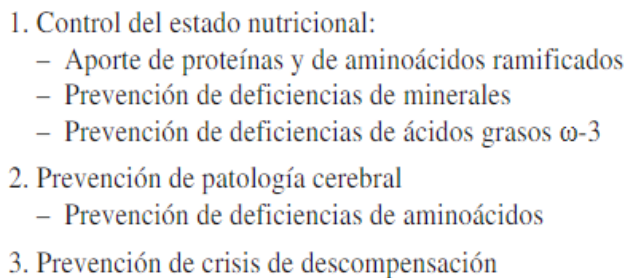

Elaborado por: Grupo de Investigación.

Otra opción de tratamiento podría ser el trasplante hepático, se ha observado una importante recuperación neurológica en el paciente a largo plazo que se sometió a trasplante y se notificaron mejoras sutiles pero claras en varios de los pacientes trasplantados recientemente. Estos hallazgos ahora se cuantifican objetivamente mediante pruebas de neurodesarrollo realizadas antes y después del trasplante en los receptores de trasplantes posteriores. ${ }^{(6,18)}$ (“Transplante de hígado...”, 2016) (Strauss, 2006)

Hay que recordar que, sin tratamiento, esta enfermedad es potencialmente mortal. ${ }^{(19)}$ (Hurst, 2017)

Los factores pronósticos dependen de la edad en que se realiza el diagnóstico ya que el desarrollo neurológico es pobre cuando el diagnóstico se realiza después de los 7 días de vida y malo cuando se realiza después de los 14 días, el grado de compromiso en el momento del diagnóstico, nivel de Leucina al momento del diagnóstico, el buen control dietario y el control de las infecciones que pueden llevar a descompensaciones metabólicas, incluso con tratamiento dietético, las situaciones estresantes y la enfermedad pueden aun causar niveles altos de ciertos aminoácidos. La muerte se puede presentar durante estos episodios. ${ }^{(7,20)}$ (Serra, 2017) (Edens, 2017)

\section{Conclusiones.}

- Los errores innatos del metabolismo entre ellos la EOJA presentan sintomatología inespecífica, por eso es indispensable para su diagnóstico sospechar ante cualquier alteración en el estado neurológico de un recién nacido.

- Además, recordar que mientras más temprano se haga el diagnóstico de esta enfermedad, mejor será su pronóstico y menos consecuencias en la calidad de vida del paciente.

- La EOJA es una enfermedad de tipo autosómico recesivo por lo que se recomienda proporcionar asesoramiento genético para los padres. 


\section{Referencias bibliográficas.}

1. Pablo Valladares, M. C. (Abril de 2012). Red de Revistas Cientificas de América Latina y el Caribe. Recuperado el 15 de Abril de 2018, de Sistema de Información Cientifica REDALYC: http://www.redalyc.org/pdf/487/48724427006.pdf

2. IQB, E. d. (11 de Julio de 2004). Instituto Quimico Biologico de España. Recuperado el Abril de 2018, de http://www.iqb.es/monografia/fichas/ficha032.htm

3. NewbornScreeningNews. (4 de Septiembre de 2014). Newborn Screening News. Recuperado el 12 de Abril de 2018, de https://www.newbornscreening.info/spanish/parent/Amino_acid/MSUD.html

4. Suárez Paola, P. F. (2015). Revista SciELO España. Recuperado el 3 de Abril de 2018, de http://scielo.isciii.es/pdf/nh/v32n1/61casoclinico01.pdf

5. Ricardo Busto, M. C. (Octubre de 2014). Revista SciELO Cuba. Recuperado el 10 de Abril de 2018, de http://scielo.sld.cu/scielo.php?script=sci_arttext\&pid=S168418242014000500013

6. RevistaABCArticulosLibres. (29 de Abril de 2016). ABC Articulos Libres. Recuperado el 15 de Abril de 2018, de http://abcarticulos.info/article/proporcionarcure-trasplantes-de-hgado-metablica-para-las-enfermedades-raras-de-orina-dejarabe-de-arce

7. Dalmau Serra, F. S. (7 de Septiembre de 2017). ResearchGateNet. Recuperado el 5 de Abril de 2018, de https://www.researchgate.net/publication/285660461_Enfermidades_de_orina_de_j arabe_arce

8. FEDER, S. d. (2015). Federación Española de Enfermedades Raras. Recuperado el 5 de Abril de 2018, de https://enfermedadesraras.org/index.php?option $=$ com_content $\&$ view $=$ article $\&$ id $=1125 \&$ Itemid $=171$

9. Ledro Carabaño, G. A. (2014). Anales de Pediatria. Recuperado el 10 de Abril de 2018, de http://www.analesdepediatria.org/es/nueva-mutacion-como-causaenfermedad/articulo/S1695403313002579/

10. Céspedes, G. d. (2013). Revista Scielo de Costa Rica. Recuperado el 17 de Mayo de 2018, de http://www.scielo.sa.cr/pdf/amc/v56n2/art10v56n2.pdf

11. Lanza, A. (2017). Biblioteca Virtual en Salud Honduras. Recuperado el 2 de Mayo de 2018, de http://www.bvs.hn/RMH/pdf/2017/pdf/Vol85-1-2-2017-9.pdf 
12. Román, L. (Octubre de 2005). Revista Scielo España. Recuperado el 8 de Mayo de 2018, de http://scielo.isciii.es/scielo.php?script=sci_arttext\&pid=S021271992005001000010

13. Wilcken, B. (Abril de 2014). Portal sobre enfermedades raras y medicamentos huerfanos. Recuperado el 3 de Abril de 2018, de ORPHANET: https://www.orpha.net/consor/cgi-bin/OC_Exp.php?Expert=268184\&lng=ES

14. Revista Médica, Grupo. (6 de Enero de 2015). Revista Médica-Junta de Beneficiencia de Guayaquil. Recuperado el 5 de Mayo de 2018, de https://www.revistamedica.org.ec/noticias/9953-la-extrana-enfermedad-que-haceque-la-orina-huela-a-jarabe-de-arce

15. Puckett RL, L. F. (1 de Mayo de 2018). Guia Metabólica de Barcelona. Recuperado el 3 de Mayo de 2018, de https://www.guiametabolica.org/noticia/enfermedadorina-jarabe-arce-msud-nueva-evidencia-deteccion-neonatal-puede-fallar

16. Haldeman, C. (15 de 05 de 2011). Pediatric Cardiology Associates. Recuperado el 6 de Mayo de 2018, de https://www.pediatrix.com/sitemaker/websitefiles/StPeteCa8950768/body_mod.cfm ?id=38\&action=detail \&AEArticleID=000373\&AEProductID=Adam2004_102\&AE ProjectTypeIDURL=APT_5

17. Aldamiz, L. (27 de Marzo de 2008). PKU.OTM. Recuperado el 10 de Abril de 2018, de http://www.euskadipkuotm.org/protocolos/12_JARABE_ARCE.pdf

18. Strauss, K. (2006). Children's Hospital Pittsburgh. Recuperado el 20 de Abril de 2018, de http://www.chp.edu/our-services/transplant/liver/education/liver-diseasestates/maple-syrup-urine-disease

19. Hurst, A. C. (5 de Enero de 2017). MedlinePlus. Recuperado el 8 de Mayo de 2018, de https://medlineplus.gov/spanish/ency/article/000373.htm

20. Edens, A. (05 de Enero de 2017). University of Maryland Medical System. Recuperado el 2 de Mayo de 2018, de https://www.umms.org/sjmc/patientsvisitors/health-library/medical-encyclopedia-spanish/articles/enfermedad-de-laorina-con-olor-a-jarabe-de-arce

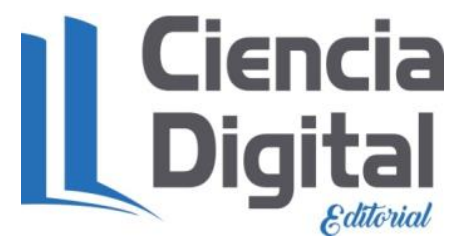


Para citar el artículo indexado.

López M. \& Vaca C. (2018). Enfermedad de la orina con olor a jarabe de arce: revisión de tres casos clínicos. Revista electrónica Ciencia Digital 2(3), 299-317.

http://cienciadigital.org/revistacienciadigital2/index.php/CienciaDigital/article/view/154/13

$\underline{9}$

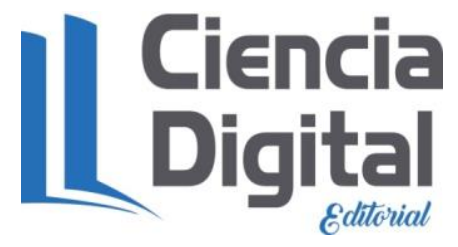

El artículo que se publica es de exclusiva responsabilidad de los autores y no necesariamente reflejan el pensamiento de la Revista Ciencia Digital.

El articulo queda en propiedad de la revista y, por tanto, su publicación parcial y/o total en otro medio tiene que ser autorizado por el director de la Revista Ciencia Digital.
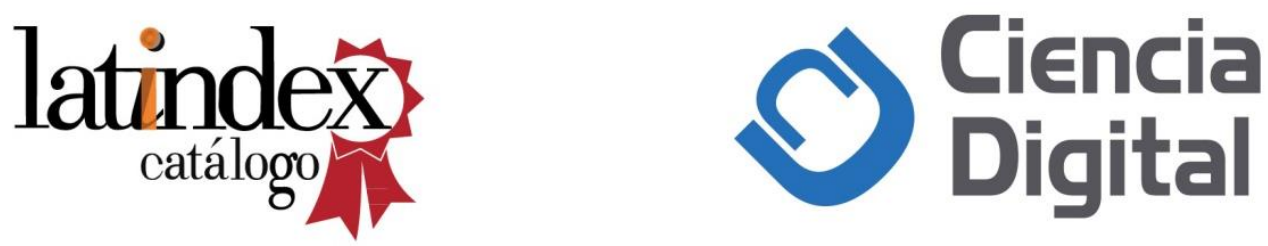